\title{
ESTUDIO DE RESTOS HUMANOS PROCEDENTES DEL DOLMEN DE CAÑADA REAL DEPOSITADOS EN EL DEPARTAMENTO DE ANATOMÍA Y EMBRIOLOGÍA HUMANAS DE LA FACULTAD DE MEDICINA DE LA UNIVERSIDAD DE SEVILLA
}

\author{
STUDY OF HUMAN REMAINS FROM THE CAÑADA REAL DOLMEN \\ DEPOSITED AT THE DEPARTMENT OF ANATOMY AND HUMAN EMBRIOLOGY \\ OF THE FACULTY OF MEDICINE, SEVILLA UNIVERSITY
}

\author{
por \\ ROSARIO CABRERO GARCÍA \\ JESÚS AMBROSIANI FERNÁNDEZ \\ JUAN MANUEL GUIJO MAURI \\ EZEQUIEL GÓMEZ MURGA
}

RESUMEN Don Juan de Mata Carriazo entregó dos lotes de huesos humanos procedentes de su excavación del Dolmen de Cañada Real: uno fue depositado en el Museo Arqueológico de Sevilla, mientras que el otro fue llevado a la Facultad de Medicina de la Universidad. Una vez publicados los resultados de los restos óseos del museo, nos detenemos aquí en la descripción de este segundo depósito.

Mr. Juan de Mata Carriazo handed over two sets of human bones from his excavation of
the 'Dolmen de Cañada Real': one was deposited at the Archaeological Museum of Seville,
while another was taken to the Medicine Faculty of the University. Once the bone remains
housed at the museum have been published, we study the second ones.

Palabras claves Megalitismo, huesos humanos, paleopatología, IV milenio a.C., Los Molares (Sevilla).

Key words Megalithism, human bones, paleopathology, IV millennium B.C., Los Molares (Seville). 


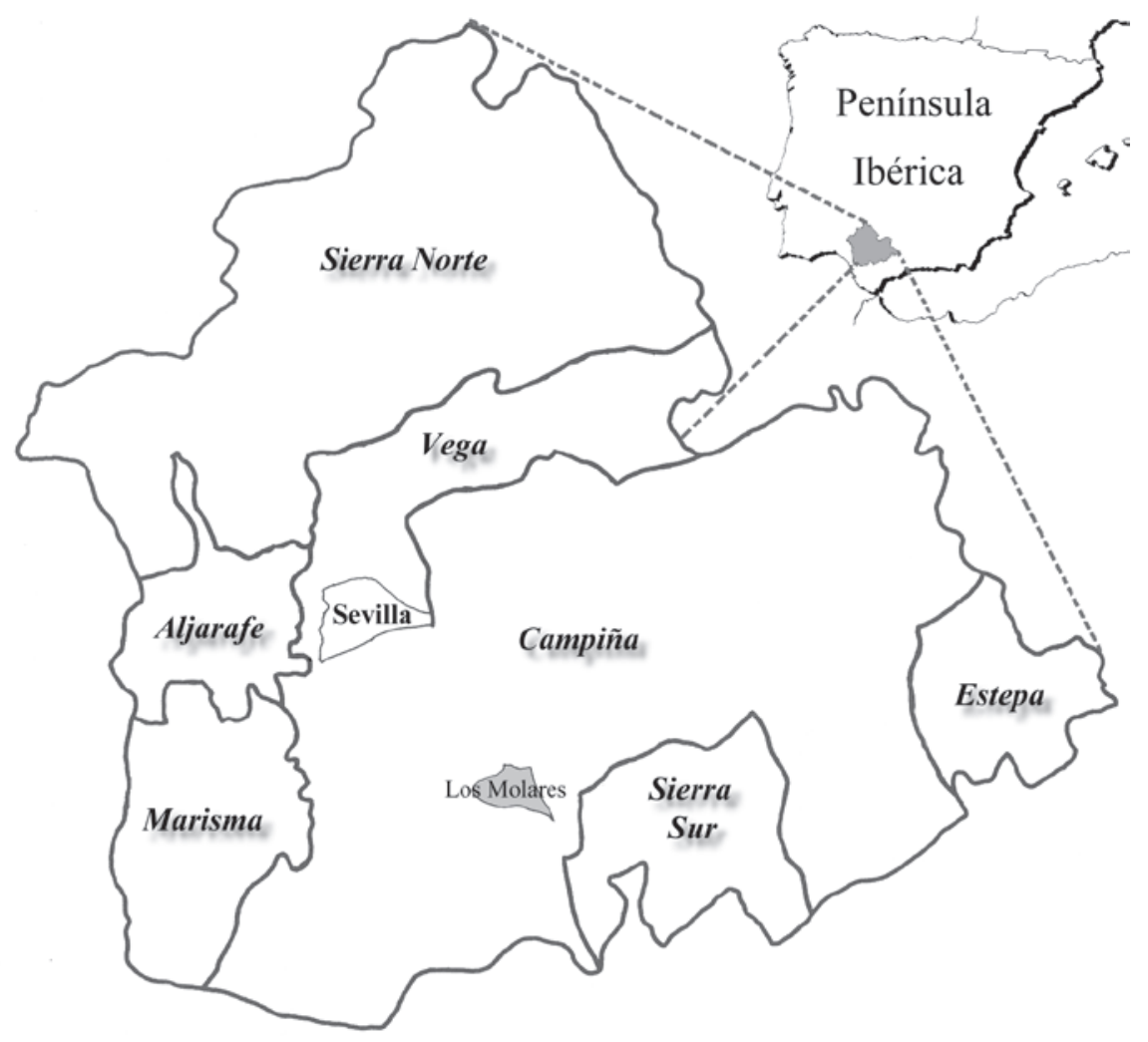

Fig. 1. La provincia de Sevilla (España) y su distribución comarcal.

El Dolmen de Cañada Real, situado en la población sevillana de Los Molares (fig. 1), concretamente en el extremo norte de su área urbana actual (fig. 2), pertenece a una necrópolis megalítica de la primera mitad del IV milenio a.n.e. ${ }^{1}$. Fue excavado por Don Juan de Mata Carriazo ${ }^{2}$ en el año 1967, según él mismo nos dice en su libro Protohistoria de Sevilla (Carriazo 1974: 152-154); aunque en realidad, como tendremos ocasión de exponer pormenorizadamente en la monografía que algunos de los firmantes de este artículo estamos preparando, el acontecimiento del hallazgo y su posterior excavación ocurrió realmente en la primavera de 1968, conforme consta en algunas de las etiquetas que acompañan al material extraído, y que han podido ser verificadas gracias a una nota existente en el Libro de Actas de Sesiones del Ayuntamiento y, fundamentalmente, gracias al testimonio de Don Manuel Sancha Blanco; por entonces maestro nacional en el pueblo, y alumno, a su vez, del Profesor Carriazo ${ }^{3}$. Él fue quien notificó la aparición del citado monumento megalítico y a quien debemos su conocimiento.

Según nos relata el propio Sr. Sancha, esa época era difícil para muchos vecinos de Los Molares, y esto se plasmaba muy a menudo en la escuela, con la ausencia continuada de algunos de sus alumnos, que tenían que ocuparse de tareas familiares o debían acompañar a sus padres, jornaleros, a la recogida de diferentes cosechas fuera del pueblo. El Ayuntamiento, presidido por Don José Pérez Hidalgo -que

1. Véase al respecto: Ruiz Delgado 1985: 66-67 y 239-240; Cabrero et alii 1993: 131-141; Cabrero et alii 1995: 191-200; Cabrero et alii 1995b: 69-79; Cabrero et alii 2003: 97-124; Cabrero et alii 2004: [en prensa]. Algunos datos paleoambientales, aunque referidos al yacimiento de El Amarguillo II -a poco más de un kilómetro de esta necrópolis-, pueden consultarse en López García y López Sáez 1997: 19-22.

2. Juan de Mata Carriazo y Arroquia (1899-1989), Catedrático de Prehistoria e Historia Antigua y Media de España en la por entonces Facultad de Filosofía y Letras de Sevilla; así como Delegado de Zona del Servicio Nacional de Excavaciones.

3. En esos años realizaba su carrera de Filosofía y Letras en la Universidad de Sevilla, licenciatura que finalizó en 1969; año también, por cierto, de la jubilación de Don Juan de Mata. 
Fig. 2. Zona norte de Los Molares en

1977.

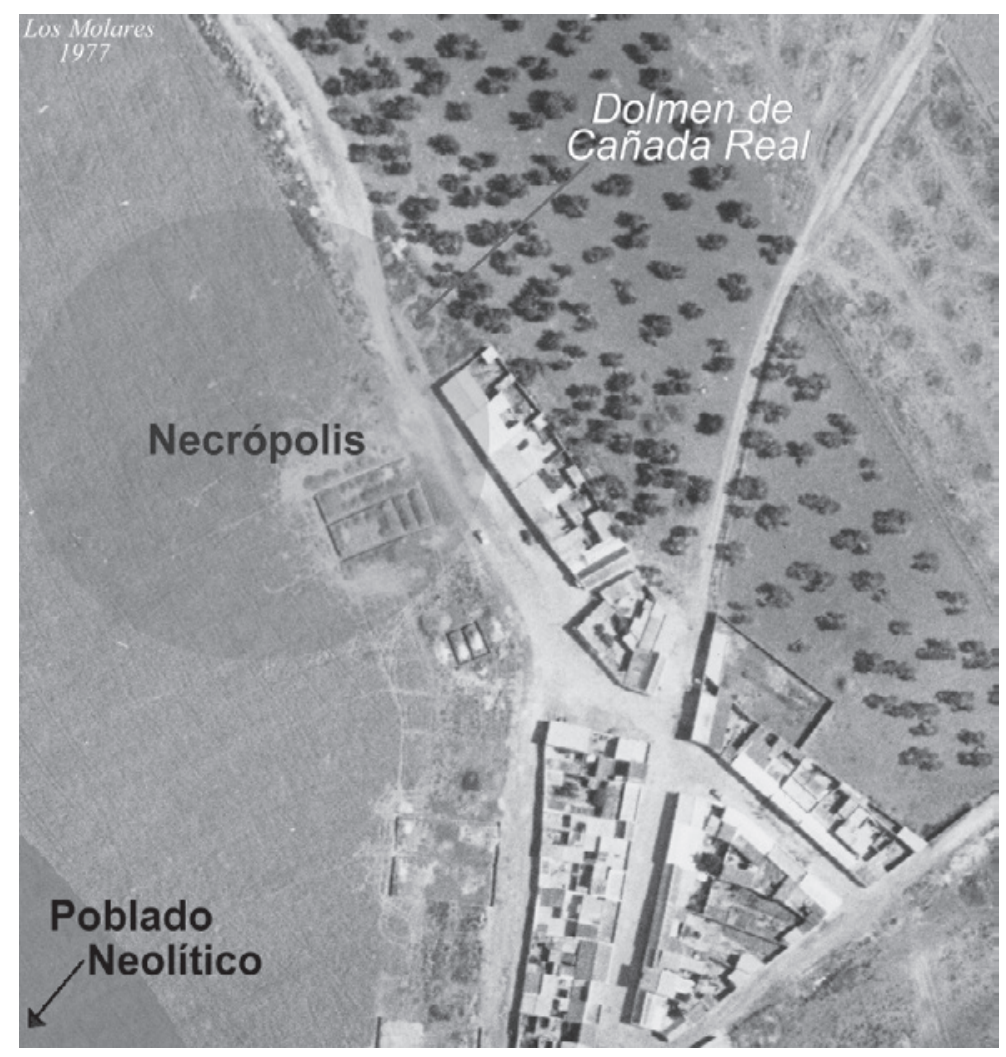

además de alcalde era maestro y director del grupo escolar-, se había sensibilizado con esta cuestión, y como ayuda para algunas de estas familias necesitadas, les permitió edificar sus casas en terrenos hasta entonces de dominio público.

Fue al realizar los cimientos de una de estas viviendas cuando quedaron al descubierto varias piedras del monumento funerario, prácticamente a ras de suelo, pues apenas quedaban restos del túmulo (sólo una pequeña parte en uno de sus extremos). Algunos vecinos del pueblo penetraron en el interior de la estructura desde arriba, como si fuera un zulo, y su acceso era bastante difícil.

Cuando llegó la noticia del extraño hallazgo a Don Manuel Sancha, éste se introdujo también en su interior y recogió varios huesos de muestra, que llevó rápidamente al despacho de Don Juan de Mata Carriazo en la Universidad, consciente de que se trataba de un "dolmen" y de que podía ser destruido si no se actuaba con rapidez. Al no encontrarse en esos momentos en su despacho el profesor Carriazo, recogió la noticia Don Manuel González, entonces profesor ayudante y hoy catedrático de Historia Medieval de la misma Universidad. Él se lo comunicó a Carriazo, quien se ocupó al instante del asunto, como Delegado de Zona que era del Servicio Nacional de Excavaciones (Carriazo Rubio 2001: 225), y se presentó enseguida, en un taxi, en el pueblo de Los Molares, acompañado de su mujer y de Don Francisco Collantes de Terán, que durante muchos años fue "la mano derecha" de Carriazo, tanto en la docencia como en excavaciones arqueológicas ${ }^{4}$.

A partir de ese momento, la guardia civil custodió el monumento megalítico y se realizó la excavación arqueológica de manera "oficial", de la que se obtuvieron algunos datos interesantes. Pero ha sido

4. Francisco Collantes de Terán y Delorme (1899-1977), además de archivero del Ayuntamiento de Sevilla, ganó por oposición una plaza de profesor adjunto contratado, que conservó hasta su jubilación en 1969 (Belén y Beltrán 2003: [en prensa]). También fue comisario provincial del Servicio Nacional de Excavaciones Arqueológicas (Carriazo 1974: 26). 
con posterioridad, tras la revisión de los materiales extraídos y las analíticas realizadas desde mediados de los años 80 , cuando se ha podido valorar en su justa medida la importancia de esta necrópolis megalíticas.

Centrándonos en el registro óseo procedente de Cañada Real, el profesor Carriazo llevó al Museo Arqueológico de Sevilla, en 1972, varias bolsas con restos humanos, que han sido estudiados y publicados por investigadores del Departamento de Prehistoria y Arqueología de la Universidad de Sevilla y del Departament de Biologia Animal, de Biologia Vegetal i d'Ecologia, Unitat d'Antropologia, de la Universitat Autònoma de Barcelona (Cabrero et alii 1993; Cabrero et alii 2004).

Pero otros restos humanos encontrados en el mismo sepulcro fueron llevados por el profesor Carriazo a la Facultad de Medicina de Sevilla, donde Jesús Ambrosiani ${ }^{6}$ los ha conservado durante todos estos años, y bajo su tutela Juan Manuel Guijo Mauri ha realizado el estudio cuyos resultados se exponen a continuación ${ }^{7}$ :

\section{ESQUELETO APENDICULAR SUPERIOR}

\section{Escápula derecha}

- Acromion y $1 / 2$ posterior cavidad glenoidea

- Morfología robusta, destacando inserciones del deltoides y trapecio. Longitud glenoidea (altura) $=+3,5 \mathrm{~cm}$

- Roturas sobre hueso seco recientes acompañadas de otras con aristas bien marcadas y trayectos regulares ejecutadas probablemente sobre hueso fresco

\section{Escápula derecha}

- Parte superior que abarca aparte de la fosa supraespinosa y arranque del acromion en el cuerpo escapular

- Caracteres morfológicos robustos y dos agujeros nutricios en el fondo de la fosa supraespinosa.

- Roturas en seco recientes y otras sobre materia fresca

\section{Escápula derecha}

- Borde axilar (1/3 inferior), zonas de inserción de los músculos redondo mayor y menor

\section{Escápula derecha}

— Borde axilar casi completo y $1 / 2$ inferior zona glenoidea

- Fracturas en seco antiguas y recientes

- Potente inserción del tríceps

- Anchura glenoidea $=26 \mathrm{~mm}$

\section{Escápula derecha}

- Porción espina y tercio interno del acromion

6 Escápula derecha (apófisis coracoides)

- Destacan inserciones de los pectorales y del coracobraquial

\section{Escápula izquierda}

— Fondo fosa supraespinosa y arranque del acromion

5. No hay que olvidar que durante muchos años, la única particularidad a destacar de esta necrópolis ha sido el esquema arquitectónico - poco frecuente- de planta en L; mientras que el desconocimiento de la entidad de sus ajuares y la ausencia de otras analíticas, provocaron hasta época muy reciente una adscripción mecánica a la Edad del Cobre.

6. Jesús Ambrosiani Fernández es en la actualidad Profesor Titular del Departamento de Anatomía y Embriología Humanas de la Universidad de Sevilla y Director de la Unidad de donaciones de cuerpos, preparación y conservación de piezas anatómicas.

7. Un fragmento de cráneo ha sido publicado anteriormente (Pecero y Guijo 1998: 191-216). 


\section{Clavícula derecha}

- Faltan extremos externo e interno

- Destaca cresta en relación a inserción deltoidea

- Semejanza morfológica con 2

9 Clavícula izquierda ( $1 / 2$ externo)

- Gran tubérculo en relación a inserción de ligamentos coracoclaviculares

- Marcada cresta de inserción deltoidea

- Longitud estimada $=+15 \mathrm{~cm}$

10 Clavícula izquierda ( $1 / 2$ externo)

- Destaca cresta inserción trapecio

11 Clavícula izquierda

- Parte externa, cara superior correspondiente a inserción del deltoides y trapecio

- Robustez generalizada

\section{Húmero derecho}

- 1/3 distal parte externa incluyendo cóndilo y epicóndilo

\section{Húmero derecho}

- Fragmento correspondiente a pieza 12

- Morfología muy robusta con inserciones musculares muy acentuadas en distal

- Presencia de calcificaciones ligamentosas en el ángulo superior de la cavidad coronoidea

- Diámetro transverso epicóndilo-epitróclea $=7 \mathrm{~cm}$

\section{Húmero derecho}

- Porción distal de la diáfisis

- Marcada cresta de inserción del primer radial externo

15 Húmero derecho ( $1 / 3$ superior diáfisis)

- Pronunciada cresta de inserción en el canal bicipital correspondiente al pectoral mayor

- Diámetro a.p. $=20 \mathrm{~mm}$; diám. tr. $=25 \mathrm{~mm}$

16 Húmero derecho (parte anterior diáfisis correspondiente tuberosidad deltoidea)

17 Húmero derecho (parte anterior diáfisis proximal y tuberosidad deltoidea)

18 Húmero izquierdo

- Epífisis proximal con grandes pérdidas de sustancia en anterior y posterior

- Diámetro cabeza humeral $=+45 \mathrm{~cm}$

- Numerosas concreciones y coloración oscura en la superficie articular

19 Húmero izquierdo

- 1/2 inferior con pérdida de la epífisis

- Claras calcificaciones ligamentosas en cavidades articulares anterior y posterior

\section{Húmero izquierdo}

- Diáfisis distal, parte posterior, incluyendo parte de la cavidad olecraniana

\section{Húmero izquierdo}

$$
\text { — Epicóndilo }
$$

\section{Humero N. I.}

- Fragmento cabeza.

\section{Radio derecho}

- Diáfisis

- Robustez generalizada destacando punto inserción pronador redondo

\section{4-25 Radio derecho}

- Parte proximal de la diáfisis y tuberosidad bicipital

— Longitud estimada $=25 \mathrm{~cm}$ 


\section{Radio izquierdo}

- Pieza completa a excepción de $1 / 5$ inferior

— Longitud conservada $=15 \mathrm{~cm}$; longitud estimada $=$ menos de $20 \mathrm{~cm}$

— Diámetro a.p. y diám. tr. $=10 \mathrm{~mm}$

— + bíceps, supinador corto, flexor largo del pulgar y abductor largo del pulgar

\section{Radio izquierdo}

$-1 / 2$ inferior

- Algunas neoformaciones óseas alrededor de la cavidad articular

— Diámetro a.p. $=2 \mathrm{~cm}$; diám. tr. $=3 \mathrm{~cm}$, correspondientes a epífisis distal

- Presencia de algunos restos de ocre

28 Radio izquierdo ( $1 / 3$ central diáfisis)

\section{Cúbito derecho}

- $1 / 4$ superior

- Morfología muy robusta: destacan inserciones de ancóneo, braquial anterior y supinador corto

\section{Cúbito derecho (olécranon)}

31 Cúbito derecho (parte lateral interna de la diáfisis)

32 Cúbito N. I. (frags. varios)

33 Escafoides izquierdo

34 Piramidal izquierdo

35 III metacarpiano derecho

36 IV metacarpiano derecho

$37 \mathrm{~V}$ metacarpiano derecho

38 I metacarpiano izquierdo

39 IV metacarpiano izquierdo

40 IV metacarpiano izquierdo

41 Falange proximal

42 Falange proximal

43 Falange medial

\section{COXAL y ESQUELETO APENDICULAR INFERIOR}

\section{COXAL}

\section{Coxal izquierdo}

- Fragmento de íleon (1/3 inf.) y 2/3 posteriores de la cavidad cotiloidea, con completa ausencia del pubis y de la mayor parte del isquion

- Presenta sólidas concreciones y manchas de ocre sobre la línea innominada

- El diámetro de la cavidad cotiloidea y la escotadura ciática mayor nos dan sexo femenino

45-46 Íleon derecho + cavidad acetabular e isquion + acetábulo

- Presentas pequeñas manchas de ocre

— La escotadura ciática mayor lo adscribe al sexo masculino

\section{FÉMURES}

\section{Derechos}

47 Diáfisis (1/4 central superior, incluyendo la trifurcación de la línea áspera)

— Diám. a.p. $=32 \mathrm{~mm}$; diám. tr. $=26 \mathrm{~mm}$ y pilastra muy marcada 
48 1/2 superior (falta la epífisis proximal)

- D. a.p. $=30$; d. tr. $=28$

49 Extremo proximal (cabeza y cuello quirúrgico)

- Profunda fosita del ligamento redondo

- D. cab. $=43 \mathrm{~mm}$

\section{Izquierdos}

50 Diáfisis (porción a la altura de la línea de trifurcación superior de la línea áspera)

- Pilastra y músculo vasto externo muy pronunciados

D. a.p. $=32$; d. tr. $=27$

\section{$51 \mathbf{1} / \mathbf{2}$ inferior}

- Presencia de concreciones y manchas de ocre

— Diámetro bitrocantéreo $=76 \mathrm{~mm}$

\section{Zona trocantérea y cuello quirúrgico}

- Marcada morfología muscular en relación a glúteo menor, vasto ext., cuadrado crural y obturador externo

53 Zona trocantérea y cuello quirúrgico (falta el trocánter menor)

- Marcadas inserciones del obturador externo (presencia de calcificaciones), glúteo menor y vasto externo

54 Cabeza femoral (falta sustancia en la zona de la fosita del ligamento redondo)

55 Porción epífisis distal, cóndilo externo, parte inferior

- Presenta leves alteraciones artrósicas

56 Porción distal, cóndilo interno y alteraciones artrósicas

57 Zona central de la diáfisis a la altura del agujero nutricio

\section{Porción diáfisis}

TIBIAS

\section{Derechas}

$59 \mathbf{1 / 3}$ inferior

- Concreciones cara anterior

60 Tercio distal

- Potentes músculos a nivel de la epífisis en su parte posterior

- Presencia de ocre en la parte posterior

- Probable relación con 62

61 Epífisis proximal

- Robustez en su morfología

— Diám. tr. ep. proximal $=+60 \mathrm{~mm}$

\section{Izquierdas}

\section{$62 \mathbf{1} / 4$ distal}

- Notable robustez (probable relación con 60)

63-64 Parte central de la diáfisis y diáfisis proximal (altura del agujero nutricio)

PERONÉS

65 Der.

66 Der.

67 Izq.: 1/2 proximal (3 frags.) 
TARSO DERECHO

68 Calcáneo

- Calcificación parcial tendón de Aquiles

- Long. $=75 \mathrm{~mm}$

69 Escafoides

70 I Cuña derecha

71 II Cuña derecha

TARSO IZQUIERDO

72 Astrágalo

- Long. $=50 \mathrm{~mm}$

- Pigmentación con ocre en su parte externa e inferior (menos acentuada en zona superior)

73 I Cuña

Metatarso derecho

74 I metat.

75 II “

76 IV “

Metatarso izquierdo

77 II metat.

78 IV “6

FALANGES PIE

79 I proximal izquierda

\section{CAJA TORÁCICA y COLUMNA VERTEBRAL}

80 Costilla izquierda

81 Costilla izquierda

82 Fragmentos inespecíficos

VÉRTEBRAS CERVICALES

83 Atlas

— Pérdida del arco posterior

- Robustez general

84 Atlas

— Parte lateral izquierda correspondiente a apófisis articulares

85 Atlas

- Arco anterior-zona articular con el axis

— Presencia de moderados osteofitos en cara articular

86 Axis

- Presencia de ocre en carilla articular superior derecha

- Sólidas concreciones

- Leves alteraciones carilla articular con el atlas

87 V. cerv. N.I.

SPAL 14 (2005)

ISSN: 1133-4525 ISSN-e: 2255-3924 http://dx.doi.org/10.12795/spal.2005.i14.02 


\section{V. cerv. N.I.}

- Calcificación parcial ligamento vertebral común posterior, deformación intensa apófisis articular superior izquierda y osteofitosis

\section{VÉRTEBRAS DORSALES}

\section{V. N.I.}

- Probablemente correspondiente a la VIII ó IX

- Hundimiento del hueso compacto en el tercio posterior de la cara inferior del cuerpo vertebral (herniación del núcleo pulposo que hunde el hueso compacto)

\section{V. N.I.}

91 V. N.I.

- Hernia intracorporal

92 V. N.I.

— Osteofitosis moderada en ambas caras, parte izquierda del cuerpo. (¿Relación escoliosis de concavidad izquierda?)

\section{V. N.I.}

- Pérdida de sustancia grande en la mitad inferior del cuerpo

- Profunda depresión del cuerpo vertebral ( $2 \mathrm{~cm}$ en sentido transverso) o hernia intraesponjosa

VÉRTEBRAS LUMBARES

\section{V. N.I.}

— Diagnóstico basado en ausencia de caras articulares para las costillas

\section{V. N.I.}

— Leves pérdidas de sustancia en el cuerpo

- Morfología muy robusta

\section{V. N.I.}

- Rotura antigua del cuerpo vertebral oblicua de arriba abajo y desde delante hacia atrás

\section{V. N.I.}

- $1 / 2$ izquierdo del cuerpo

- Osteofitos leves en el borde inferior del cuerpo

\section{Quinta vértebra lumbar}

SACRO

99

100

OTROS

101 Hioides

\section{CRÁNEO}

\section{Fragmentos}

\section{ESQUIRLAS}

\section{Esqueleto poscraneal}


Los restos humanos descritos aquí han sido entregados a la Delegación Provincial de Cultura de la Junta de Andalucía en diciembre de 2003.

El pequeño fragmento de cráneo de un individuo enterrado en el Dolmen de Cañada Real publicado por J. C. Pecero Espín y J. M. Guijo Mauri (1998), procede también del conjunto de restos humanos depositados por Don Juan de Mata Carriazo y Arroquia en la Facultad de Medicina de Sevilla. Se utilizó para una investigación que, con carácter general, abordaba la problemática tafonómica, biológica y edafológica del contexto osteológico, y su aplicación para entender el registro funerario de la Edad del Bronce; concretamente en el caso práctico de los restos óseos hallados en la cista número 5 de La Traviesa (Almadén de la Plata, Sevilla).

En este artículo se pone de relieve la "necesidad de comprender la naturaleza de la conservación del material, así como de valorar la cronología del conjunto de alteraciones deposicionales de la evidencia esquelética".

Mediante la descripción de los sedimentos asociados al hueso y, por otra parte, de las alteraciones y marcas de los mismos", se fueron delimitando una serie de agentes "bióticos y abióticos". Como contrastación empírica se realizó un estudio comparativo con diversos fragmentos -de hueso occipital y parietal, de fémur y húmero- procedentes de otros contextos edafológicos. Estos materiales comparativos procedían de:

“- Dolmen de Cañada Real, Los Molares-Sevilla (suelo básico). Edad del Cobre.

- Necrópolis de Gilena. Sevilla (suelo básico). Edad del Cobre.

- Cuartel del Carmen, Sevilla (suelo arenoso). Bajomedieval cristiano.

— La Rosaleda, Cádiz (suelo básico muy rico en material orgánico). Principios siglo XVIII.

Todos los referentes óseos proceden de individuos adultos de sexo masculino, en un intento de minimizar en lo posible las diferencias con la caracterización antropológica de la inhumación que estudiamos" (Pecero y Guijo 1998: 195).

Cuando se alude a "Tipología de Alteraciones Osteológicas", se señalan procesos mecánicos (roturas sobre hueso seco o desprovisto de sustancia orgánica / roturas sobre hueso provisto de materia orgánica) y alteraciones del medio edafológico y orgánico, con ejemplos concretos en cada caso. Es en este último apartado donde se ha incluido la muestra procedente del Dolmen de Cañada Real; pues su análisis microscópico dio como resultado la ausencia en ella de las agresiones siguientes:

- Erosiones y estriaciones inducidas por el medio geológico (partículas de sílice) y un medio orgánico abundante (Pecero y Guijo 1998: 198-199).

- Agrietamientos y fisuraciones superficiales provocadas por suelos ricos en materia orgánica (Pecero y Guijo 1998: 199).

Se incluye, además, la fotografía al microscopio (x 20) del tejido craneal estudiado (Pecero y Guijo 1998: 201, fig. IV.8).

\section{Estudio anatómico y patológico de los restos humanos del Dolmen de Cañada Real depositados en el Museo Arqueológico de Sevilla (Cabrero et alii 2004)}

Extractamos a continuación los resultados de los estudios anatómicos y patológicos efectuados a los restos humanos depositados por Carriazo en el Museo Arqueológico de Sevilla, y que han sido

8. Patrón de roturas, coloración, alteraciones superficiales y de sección, y características histológicas del hueso postdeposicional en relación a la histología normal del tejido humano (Pecero y Guijo 1998: 195). 
Fig. 3. Vértebra lumbar (LM-8) de R.E.P. 14315, en la que se aprecia un importante nódulo de Schmorld.

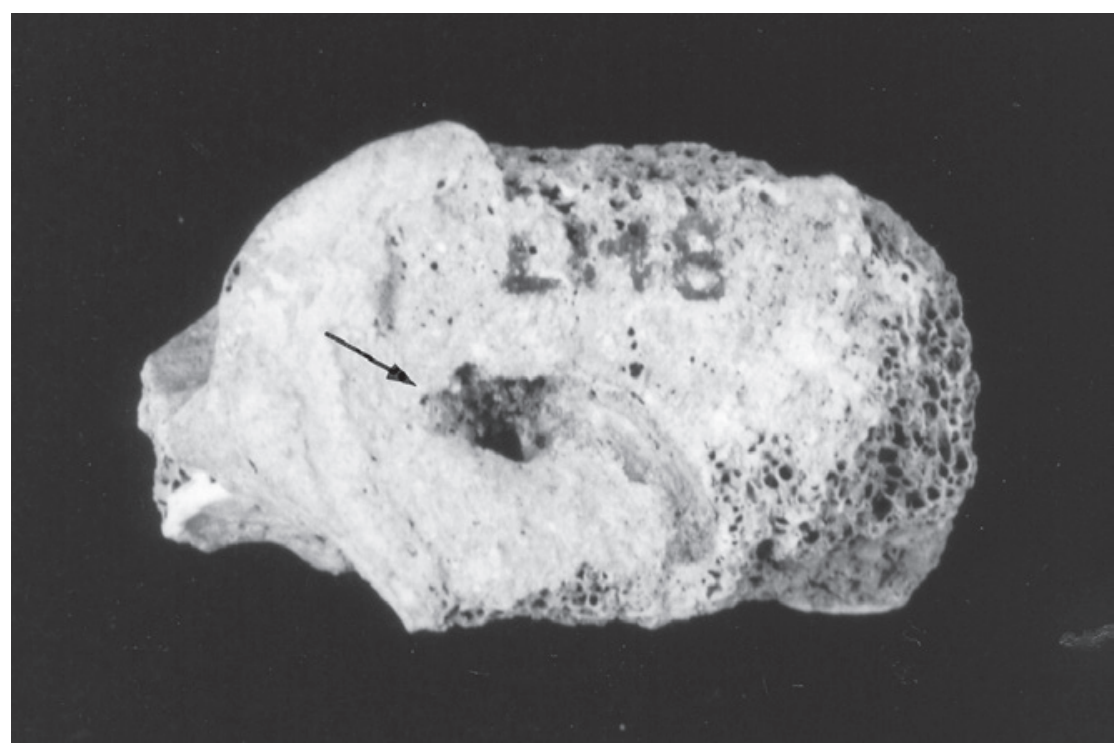

presentados recientemente en el $34^{\text {th }}$ International Symposium On Archaeometry (Zaragoza, 2004) por algunos de los firmantes de este artículo y por miembros del Departament de Biologia Animal, de Biologia Vegetal i d'Ecologia, Unitat d'Antropologia, de la Universitat Autònoma de Barcelona9.

Para estos análisis se ha optado por respetar la numeración arqueológica original, aunque somos conscientes de que esta agrupación puede no responder siempre a una separación manifiesta en el contexto arqueológico.

\section{R.E.P. 14315.}

(Bolsa que contiene exclusivamente restos óseos).

- Fragmentos craneales, vértebras, tibias, tarso y metatarso, que parecen indicar la presencia de un solo individuo.

— Edad: El tamaño y grosor de las piezas óseas, así como las epífisis soldadas de los metatarsianos y metacarpianos, y un fragmento de sutura lambdática -situada entre el parietal y el occipital- que ha empezado a obliterarse, indican la edad adulta del individuo. Los bordes superior e inferior del cuerpo de las vértebras que se conservan son bastante completos, sin alteraciones ni signos artrósicos; lo cual es típico de un individuo relativamente joven.

- Sexo: Los huesos tienen un aspecto bastante robusto y, a pesar de que ningún hueso largo se encuentra intacto para poder ser asignado a un sexo concreto, el tamaño de los huesos del pie parecerían más propios de un individuo masculino. También los fragmentos craneales son medianamente gruesos con la presencia de inserciones musculares fuertes y de una cresta supramastoidea, características que normalmente se asocian al sexo masculino.

- Patologías: Dos vértebras patológicas (LM-5 y LM-8 (fig. 3)). Ambos huesos presentan nódulos de Schmorld ${ }^{10}$. También se puede apreciar una entesopatía en el canal flexor del astrágalo (LM-2), posiblemente provocada por algún sobre-esfuerzo de la musculatura del primer dedo del pie. Tanto

9. Assumpciò Malgosa Morera, Santiago Safont Mas y M. Eulàlia Subirà de Galdàcano. El método de trabajo y algunas conclusiones de este estudio ya fueron adelantados en Cabrero et alii 1993: 131-141.

10. Se trata de lesiones de tamaño variable que se observan en los cuerpos vertebrales en forma de surcos o pequeños hundimientos, y que normalmente son producidas por sobre-esfuerzos musculares de la columna que resultan en microtraumatismos y hundimientos de las caras externas de los cuerpos vertebrales. 
la lesión vertebral como la anomalía entesopática se relacionan bien con la robustez y sexo del individuo, así como con una posible dureza del modo de vida, pero no con la edad.

R.E.P. 14316:

(Bolsa de artefactos y ecofactos hallados en el túmulo).

- Individuo muy fragmentario: un segmento de fémur y diversas astillas óseas.

— Edad: El grosor del fragmento de fémur permitiría atribuir al individuo una edad adulta.

R.E.P. 14317.

(Bolsa de artefactos y ecofactos recogidos en el interior de la cámara transversal).

- Fragmentos de diverso tamaño, cuyo estudio anatómico revela la existencia de dos individuos: un adulto y un subadulto. Este último se ha diagnosticado a partir de una costilla cuyas dimensiones no se pueden relacionar con ningún otro fragmento óseo del mismo individuo.

- Edad: No es posible indicar la edad del individuo subadulto, puesto que se carece del extremo distal de la costilla, aunque probablemente pertenecería a un niño.

- Sexo: Los restos del individuo adulto podrían atribuirse a un individuo grácil y, por tanto, posiblemente femenino; como se puede deducir por el fragmento de clavícula izquierda, así como por la levedad de los relieves musculares en las diáfisis de los huesos del antebrazo y en el peroné.

R.E.P. 14318.

(Bolsa que contiene exclusivamente restos óseos).

- Fragmentos de huesos largos, de omoplato y de coxal, así como del tarso. Todos los huesos presentan un estado de conservación poco favorable para su reconstrucción y diagnóstico, pero a pesar de ello los restos no pueden ser atribuidos a más de un individuo. Destaca la presencia de un fragmento óseo incinerado (LM-CR-II-17), pero la conservación de la estructura original del hueso, la ausencia de fracturas transversales así como su coloración, parecen indicar que las temperaturas sufridas por el hueso no fueron excesivas; todo ello induce a pensar en una incineración accidental del resto óseo más que en un tratamiento funerario diferencial.

- Sexo: el fragmento de pubis izquierdo encontrado presenta un ángulo púbico bastante cerrado, lo que permite asignarlo, en principio, al sexo masculino; si bien se trata de un único carácter, no de un hueso entero. La robustez de los fragmentos diafisarios, el tamaño de la epífisis distal del fémur y de los huesos del tarso, así como el aspecto general de la escápula, parecen confirmar este diagnóstico. Las dimensiones de la cavidad glenoidea (21,6 x 10,4 mm) indicarían, sin embargo, un individuo de sexo femenino.

- Edad: los fragmentos de cresta ilíaca del hueso coxal y la epífisis distal de una falange proximal del pie muestran la edad adulta del individuo. La sínfisis púbica, utilizada como indicador de edad, muestra un individuo bastante joven (20-25 años), puesto que no se observa la formación de bordes óseos en ella.

R.E.P. 14320

(Bolsa con artefactos y ecofactos procedentes del interior del dolmen).

- Fragmentos de diáfisis y epífisis de huesos largos, falanges y otros fragmentos (vértebras, costillas, clavículas y omoplatos). El análisis morfológico de los huesos indica la presencia de al menos dos individuos; hecho deducible de las falanges proximal y media del tercer dedo de la mano, que presentan unas características diferentes de tamaño y robustez, de forma que no articulan entre sí. Al mismo tiempo, dos fragmentos de cúbito (LM-CR-I-50 y LM-CR-I-60) son suficientemente diferentes en cuanto a robustez, inserciones musculares y tamaño como para permitir diferenciar dos individuos. 
- Edad: Puesto que las epífisis de las falanges anteriormente citadas se encuentran soldadas con las diáfisis se puede afirmar la edad adulta de los dos individuos. La misma indicación viene dada por el estado de la cresta iliaca. El único molar inferior encontrado presenta muy poco desgaste, lo cual indicaría una edad de 17-25 años.

- Patologías: El molar no presenta caries ni cálculo dental; la observación del alvéolo confirma la ausencia de enfermedad periodontal y por consiguiente de periostitis: todo ello es más propio de un individuo joven. Por otro lado, en el fragmento de sacro (LM-CR-I-3) se puede observar la presencia de una hernia discal producto de una dismorfogénesis lumbo-sacra; lo cual es indicativo de una sobrecarga en la espalda.

Síntesis

A partir de los datos obtenidos de las bolsas existentes en el Museo Arqueológico de Sevilla, se puede afirmar la existencia de al menos siete individuos enterrados en el Dolmen de Cañada Real, siempre y cuando la numeración arqueológica corresponda a enterramientos diferentes. Se puede deducir la presencia de cinco adultos, un subadulto y un individuos de edad y sexo desconocidos, distribuidos del siguiendo modo:

$\begin{array}{ll}\text { R.E.P. } 14315 & \text { masculino de edad superior a } 30 \text { años } \\ \text { R.E.P. } 14316 & \text { edad y sexo indeterminados probablemente adulto } \\ \text { R.E.P. } 14317 \mathrm{a} & \text { adulto femenino de edad indeterminada. } \\ \text { R.E.P. } 14317 \mathrm{~b} & \text { subadulto } \\ \text { R.E.P. } 14318 & \text { adulto masculino de } 20-25 \text { años } \\ \text { R.E.P. } 14320 \mathrm{a} & \text { adulto de sexo desconocido y } 17-25 \text { años } \\ \text { R.E.P. } 14320 \mathrm{~b} & \text { adulto de sexo y edad desconocidos }\end{array}$

Sin embargo, prescindiendo de las referencias que acompañaban a los huesos, únicamente se puede deducir la presencia de un mínimo de tres individuos: dos adultos, probablemente de ambos sexos y de edades no excesivamente elevadas, y un subadulto.

En conclusión, los individuos enterrados en el Dolmen de Cañada Real no tendrían una edad muy avanzada y estarían representados por los dos sexos. Las escasas patologías halladas deben atribuirse a la reducida representación ósea y al precario estado de conservación. A pesar de ello, la presencia de nódulos de Schmorld y entesopatías en un individuo y una hernia discal en otro, ambos relativamente jóvenes, son exponentes de las duras condiciones de vida de la población; puesto que estas lesiones se asocian a sobrecarga de tipo muscular y a microtraumatismos producidos por pesadas cargas en la espalda.

\section{CONCLUSIONES}

El Dolmen de Cañada Real sirvió como contenedor a varios individuos que fueron enterrados en su interior en momentos diferentes; circunstancia atestiguada por Don Juan de Mata Carriazo y Arroquia, director de la excavación arqueológica:

«Mientras una de las dos naves, la que se orienta Este-Oeste, aproximadamente, carecía de cualquier ajuar, la otra nave, Norte-Sur, había conservado su relleno antiguo, que dejaba un pequeño hueco debajo de las 
cubiertas. Sus filtraciones, sin embargo, habian destruido casi por completo los restos humanos depositados en el nivel inferior de los dos que se acusaron en la excavación, mientras que, inexplicablemente, en el nivel superior pudimos retirar un cráneo casi completo, partes de otro y algunos huesos largos, e incluso costillas y molares.» (Carriazo 1974: 153).

Los restos humanos reunidos en este artículo permiten hacer una serie de consideraciones importantes. El primer listado, realizado por J. M. Guijo Mauri en el Departamento de Anatomía y Embriología Humanas de la Facultad de Medicina de la Universidad de Sevilla, bajo la supervisión de J. Ambrosiani, sólo permite atribuir esos restos a un mínimo de dos individuos, uno de sexo femenino y otro masculino. En ese estudio se alude en numerosas ocasiones a vestigios de ocre en diferentes huesos humanos y a algunas patologías, como hernias.

Existe la posibilidad de que en el mismo Departamento de Anatomía y Embriología Humanas haya más restos humanos de individuos enterrados en el Dolmen de Cañada Real, además de los primeros inventariados al principio del trabajo. El problema radica en que se requiere localizarlos entre otros muchos procedentes del Cuartel del Carmen y de otros lugares. Se precisa para ello una laboriosa tarea que queremos iniciar de inmediato $\mathrm{y}$, una vez finalizada la búsqueda, que promete ser de enorme interés si se encuentran los ecofactos aludidos, realizaremos un trabajo de conjunto que complete los ya existentes para calcular el número de individuos enterrados, sus edades, sexo, patologías y otras aportaciones importantes que complementen las aquí indicadas.

De todo lo anteriormente expuesto se deduce que se hace evidente la necesidad de un último estudio de conjunto que incluya una revisión de los vestigios humanos incluidos en este trabajo, a la que ha de añadirse la investigación pormenorizada de los que presumiblemente quedan por localizar. De esta manera quedaría cumplido lo que sin duda creemos habría sido el deseo del profesor Carriazo. Y sólo así podremos aproximarnos con mayor propiedad al conocimiento del contenido real de este contenedor, que queremos dar a conocer de la manera más completa posible, junto con los restantes elementos conservados que componían esta necrópolis megalítica, aún en parte inéditos.

La Necrópolis Megalítica de Los Molares es, por el momento, el conjunto dolménico más antiguo de Andalucía Occidental, junto con el Dolmen de Alberite (Villamartín, Cádiz), según la cronología absoluta que ha podido obtenerse en ambos lugares ${ }^{11}$. Sin duda alguna, el artículo que hoy presentamos y los estudios que esperamos continuar en breve, serán esenciales para precisar la Historia de este monumento, la Historia de esta necrópolis y de este hábitat (fig. 4), y la Historia de la campiña sevillana, que ocupa un destacado lugar, en este caso, en la Historia (Prehistoria) de la Península Ibérica por su antigüedad.

\section{BIBLIOGRAFÍA}

ARTEAGA, O.; SCHULZ, H. D. y ROOS, A. M. (1995): “El problema del 'Lacus Ligustinus'. Investigaciones geoarqueológicas en torno a las marismas del Bajo Guadalquivir", Tartessos, 25 años después, Jerez de la Frontera: 99-135.

BELÉN DEAMOS, M. y BELTRÁN FORTES, J. (2003): "Un siglo de Arqueología en la Universidad de Sevilla (1860-1960)", Conferencia del ciclo Las Instituciones en el desarrollo de la Arqueología en España (jueves, 13 de marzo de 2003), Spal Monografias: [en prensa].

11. En la Necrópolis Megalítica de Los Molares, uno de los individuos hallados en el Dolmen de El Palomar ha sido fechado por ${ }^{14} \mathrm{C}$ en $4930 \pm 70$ B.P. (3776-3648 a.n.e.) (Cabrero et alii 1993: 136; Cabrero et alii 2003: 98); el Dolmen de Alberite dispone de varias dataciones radiocarbónicas: $5320 \pm 90$ B.P. (4255-4000 a.n.e.), 5110 140 B.P. (4035-3760 a.n.e.) y $5020 \pm 70$ B.P. (3940-3845 a.n.e) (Ramos y Giles 1996: 184-186). 


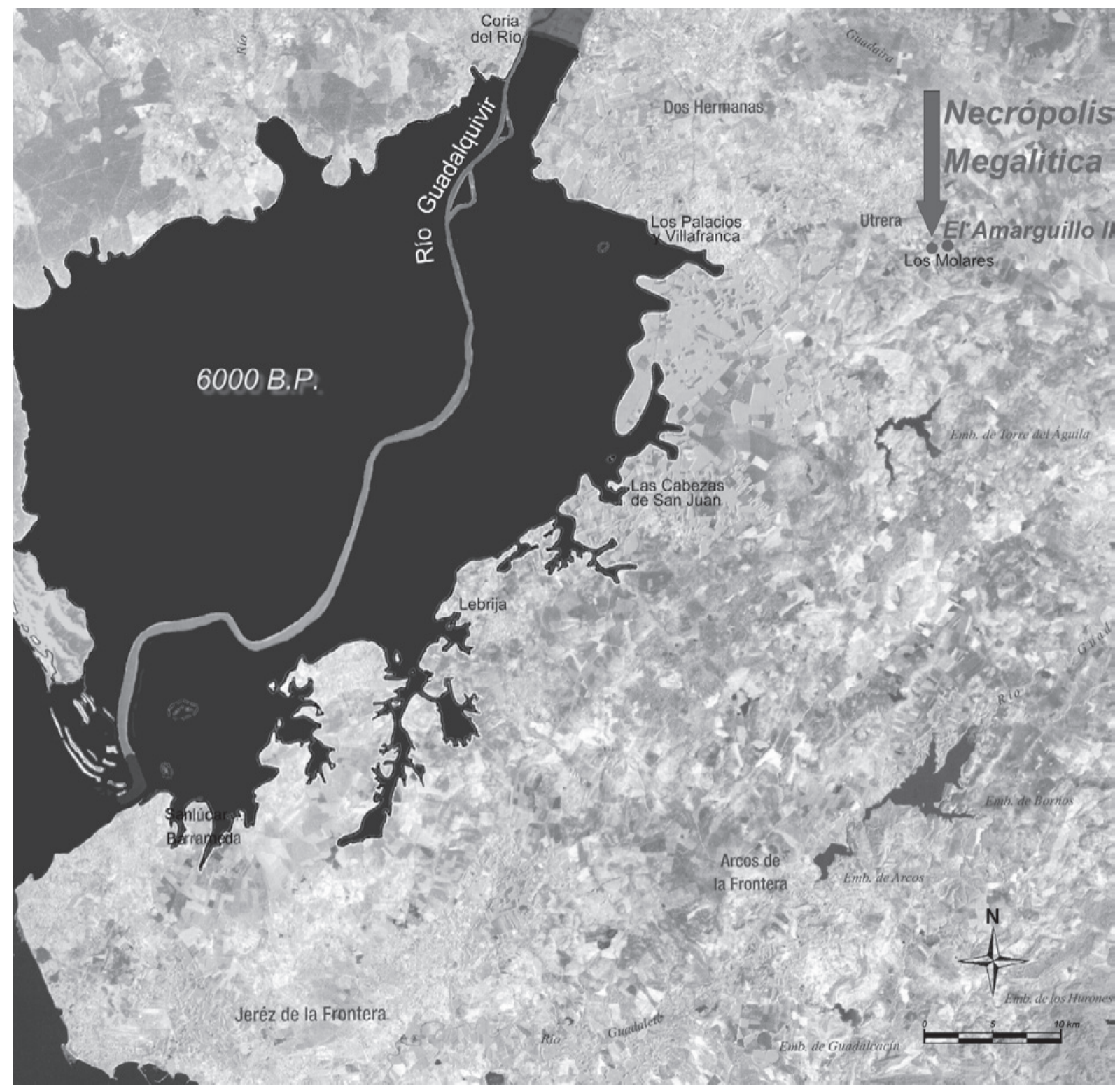

Fig. 4. Paleodesembocadura del río Guadalquivir en un golfo marino, hacia 6000 B.P. (Arteaga et alii 1995), sobre imagen de satélite actual: Es un paisaje que pervive durante toda la Prehistoria Reciente, si bien el proceso de colmatación del golfo marino, acentuado por la deforestación y la explotación agrícola de las sociedades del IV y III milenio a.n.e., provocará la emersión de pequeños islotes, y finalmente una formación deltaica. 
CABRERO GARCÍA, R.; RUIZ MORENO, M. T.; CUADRADO MARTÍN, L. B.; SABATÉ DÍAZ, I.; MALGOSA MORERA, A.; VALVERDE LASANTA, M.; SAFONT MAS, S.; GONZÁLEZ RODRÍGUEZ, M.; SUBIRÀ DE GALDÀCANO, M. E.; GONZÁLEZ VILCHES, M. C.; PASCUAL MARTÍNEZ, E. y BARDERA SOLER DE MORELL, R. (1993): "El poblado metalúrgico de Amarguillo II en los Molares (Sevilla) y su entorno inmediato en la campiña: últimas analíticas realizadas", Anuario Arqueológico de Andalucía Vol. II: 131-141.

CABRERO GARCÍA, R.; RUIZ MORENO, M. T.; SABATÉ DÍAZ, I.; CUADRADO MARTÍN, L. B. (1995): "Artefactos de tradición neolítica en sociedades prehistóricas de la provincia de Sevi1la: Cronología y cambio cultural", I Congrés del Neolitic a la Península Ibèrica, Gavà-Bellaterra, Rubricatum I, 1996, Vol. 1: 191-200.

CABRERO GARCÍA, R.; OLIVA ALONSO, D.; MALGOSA MORERA, A.; SAFONT MAS, S.; RUIZ MORENO, M. T.; SUBIRÀ DE GALDÀCANO, M. E.; SABATÉ DÍAZ, I. y BARDERA SOLER DE MORELL, R. (1995b): “Arqueometría antropológica en el sepulcro megalítico de El Palomar: Contribución al conocimiento histórico de la campiña sevillana", Spal 4: 69-79. http:// dx.doi.org/10.12795/spal.1995.i4.03

CABRERO GARCÍA, R.; VALVERDE LASANTA, M.; PASCUAL MARTÍNEZ, E.; OLIVAALONSO, D. y GÓMEZ MURGA, E. (2003): "La necrópolis megalítica de Los Molares: Estudio lítico preliminar de la industria tallada y pulimentada de Cañada Real y El Palomar. Análisis de caracterización de la materia prima, morfológico, técnico y tipométrico", Spal 12: 97-124. http://dx.doi.org/10.12795/ spal.2003.i12.05

CABRERO GARCÍA, R.; MALGOSA MORERA, A.; SAFONT MAS, S.; SUBIRÀ DE GALDÀCANO, M. E. y GÓMEZ MURGA, E. (2004): "Anatomo-pathological study of the human remains coming from the Dolmen de Cañada Real housed at the Archaeological Museum of Seville (Spain)", $34^{\text {th }}$ International Symposium on Archaeometry, 3-7 May 2004, Zaragoza, Spain. [Versión condensada para su publicación (2006): Institución "Fernando el Católico" (Excma. Diputación de Zaragoza), www.dpz.es / Institución Fernando el Católico / Libros en Red: 571-576]

CARRIAZO RUBIO, J. L. (ed.) (2001): Juan de Mata Carriazo y Arroquia. Perfiles de un Centenario (1899-1999). Universidad de Sevilla.

CARRIAZO Y ARROQUIA, J. de M. (1974): Protohistoria de Sevilla, Sevilla.

LÓPEZ GARCÍA, P. y LÓPEZ SÁEZ, J. A. (1997): "Contribución al conocimiento de la historia de la vegetación de la provincia de Sevilla: Análisis polínico del yacimiento arqueológico de «Los Molares»", Mediterránea. Serie de estudios biológicos 16: 19-22.

PECERO ESPÍN, J. C. y GUIJO MAURI, J. M. (1998): "Evidencias Osteológicas de la Necrópolis de La Traviesa: Caracterización Antropológica y Tafonómica", La Traviesa. Ritual Funerario y Jerarquización Social en una Comunidad de la Edad del Bronce de Sierra Morena Occidental, L. García Sanjuán (Editor), Spal Monografías I: 191-216.

RAMOS MUÑOZ, J. y GILES PACHECO, F. (1996): El Dolmen de Alberite (Villamartín). Aportaciones a las formas económicas y sociales de las comunidades neolíticas en el noroeste de Cádiz, Universidad de Cádiz y Ayuntamiento de Villamartín.

RUIZ DELGADO, M. M. (1985): Carta arqueológica de la campiña sevillana. Zona Sureste I, Universidad de Sevilla. 